\title{
Germination of Fully Developed Corylopsis Seeds Influenced by Harvest Date and Cold Stratification
}

\author{
Ji Hee Kim and Jeung Keun Suh \\ Department of Environmental Horticulture, Dankook University, Cheonan, \\ Chungnam 31116, Korea
}

Seong-Tak Yoon

Department of Crop Science and Biotechnology, Dankook University, Cheonan, Chungnam, 31116, Korea

Pablo Jourdan

Department of Horticulture and Crop Science, Ornamental Plant Germplasm Center, Ohio State University, Columbus, OH 43210

Mark S. Roh ${ }^{1}$

Department of Horticultural Science, Mokpo National University, Youngsan-ro, Cheonggye-myeon, Muan-gun, Jeonnam 58554, Korea

Additional index words. Corylopsis coreana, Corylopsis gotoana, fully developed seeds, physiological seed dormancy, X-ray imaging

\begin{abstract}
Corylopsis seed germination tests were conducted to assess the influence of harvest date (seed maturity) and cold stratification (CS) at $5^{\circ} \mathrm{C}$. Corylopsis gotoana seeds harvested on 12 July, 2 and 22 Aug., 6 and 20 Sept., and 1 and 10 Oct. 2011 were immersed in water for 20 min to separate fully developed seeds (full seeds) from empty seeds by floatation, and by $X$-ray scanning to identify full from empty seeds (Expt. 1). Immersing seeds in water did not effectively separate full seeds from empty seeds as evaluated by seed germination tests. Seeds harvested on or around 6 Sept. that sank showed translucent $\mathrm{X}$-ray images with fully developed internal structures composed of embryo, cotyledons, and endosperm, and were considered mature. Without $\mathrm{CS},>12 \%$ seeds harvested on 20 Sept. germinated, regardless of whether seeds were full or empty. Seeds of $C$. coreana harvested on 5 and 15 Sept., and 5 and 18 Oct. were stored dry at $20^{\circ} \mathrm{C}$ until 27 Dec. and germinated after 0, 3, 6, 9, and 12 weeks of CS (Expt. 2). Longer than 6 weeks of CS was required to accelerate and increase the germination of seeds harvested on or after 5 Sept. Germination percentage of full seeds harvested on Oct. 18 was increased to $>72 \%$ as the duration of CS treatment increased to 12 weeks. In conclusion, fully developed seeds harvested on or after 6 Sept. were considered mature and 6 weeks of CS accelerated germination and increased the germination percentage. Further, dormancy of Corylopsis seeds appears to be shallow since germination occurred without any CS.
\end{abstract}

Corylopsis Siebold \& Zucc. is a genus of about 30 species in the Hamamelidaceae family, comprised of shrubs native to eastern Asia cultivated for very early spring blooms and attractive autumn foliage (Roh et al., 2007). Germination of seeds in many woody plants, including Corylopsis, requires a period of warm stratification (WS) at $20^{\circ} \mathrm{C}$ followed by cold stratification (CS) at $5{ }^{\circ} \mathrm{C}$ to break dormancy (Baskin et al., 2002; Batlla and Benech-Arnold, 2003; Dirr, 1990). The principal characteristics of dormancy have been

Received for publication 19 Mar. 2018. Accepted for publication 25 June 2018.

Careful review and comments by. Paul Read, University of Nebraska, are greatly appreciated. Comments from anonymous reviewers during the review processes are greatly appreciated.

${ }^{1}$ Corresponding author. E-mail: marksroh@gmail. com. thoroughly reviewed (Baskin and Baskin, 2004; Bewley, 1997; Finch-Savage and Leubner-Metzger, 2006; Hilhost, 2007). However, gaps still remain in our understanding of dormancy involving various taxa, including Corylopsis.

Mature Corylopsis seeds showed fully developed internal structure of vegetative organs when examined by X-ray imaging (Kim et al., 2016, 2017). Although dry seeds stored at $5{ }^{\circ} \mathrm{C}$ for two years germinated (J.H. Kim, unpublished data), no clear or definitive documentation of desiccation tolerance in Corylopsis seeds is available. Therefore, the nature of dormancy in Corylopsis seeds is not well understood: if seeds exhibit deep or nondeep physiological dormancy, morphological dormancy with underdeveloped embryo, or physical dormancy imposed by the seedcoat. In a few woody plant species with physiological and/or morphological dormancy, seed dormancy can be released, for example, by WS at $20{ }^{\circ} \mathrm{C}$ and by $\mathrm{CS}$ at $5{ }^{\circ} \mathrm{C}$. To maximize the germination it is necessary to understand the upper limit of CS and/or lower limit of WS.

Corylopsis glabrescens seeds were described as requiring 3 to 5 months of WS followed by 3 months of CS before germination (Dirr, 1990); however, C. coreana and C. sinensis var. calvescens seeds germinated readily at more than $90 \%$ after 1 month of WS and 2 months of CS and a few seeds germinated at $10{ }^{\circ} \mathrm{C}$ without cold treatment (Roh et al., 2008). When freshly harvested seeds of $C$. coreana were subjected to WS at either $15-25{ }^{\circ} \mathrm{C}$ or $18.5 / 18{ }^{\circ} \mathrm{C}$ (day/night) without subsequent $\mathrm{CS}$, germination rate was very low (Roh et al., 2004). Thus, differences in the germination requirements of different species of Corylopsis appear to exist. Other studies (Kim et al., 2016) suggest that chemical inhibitors may also play a role in the dormancy of Corylopsis seeds as indicated by the increase in germination of C. sinensis var. calvescens seeds after immersion in water for $16 \mathrm{~h}$ or after treatment with ethanol.

There are no reports on the time of harvesting mature Corylopsis seeds to ensure maximum germination. If the embryo was not mature when fruits were harvested early, seeds will not germinate, which has never received adequate attention. In Styrax japonicus Siebold \& Zucc., immature seeds did not show well-developed embryo and cotyledons when evaluated by magnetic resonance imaging (MRI) and it was possible to achieve $>80 \%$ germination in mature seeds harvested 12-16 weeks after anthesis (Roh et al., 2004).

To maximize germination percentages of Corylopsis seeds, empty seeds that float when immersed in water should be separated from fully developed and mature seeds that sink, followed by optimum CS treatment. Immersing seeds of $C$. sinensis var. calvescens in water for $16 \mathrm{~h}$ increased the number of full seeds that germinated without CS (Kim et al., 2017), suggesting that physiological dormancy is not deep and dormancy inducing substance(s) present in the seedcoat may have been leached out. X-ray images of $C$. coreana seeds were used to separate fully developed mature seeds with developed internal structure from empty seeds, and many seeds can be imaged simultaneously by X-ray imaging to select full seeds on a large scale in Corylopsis (Kim et al., 2017). It was also possible to understand the internal structures generating full and well-developed seeds with translucent images of castor bean (Ricinus communis L.) seeds to improve the seed lot quality and germination (Carvalho et al., 2010).

Information on germination of Corylopsis seeds as influenced by seed maturity and $\mathrm{CS}$ at $5{ }^{\circ} \mathrm{C}$ is not readily available. Therefore, these experiments were designed a) to separate fully developed seeds from empty seeds by X-ray imaging and $b$ ) to investigate the seed germination of $C$. coreana and 
C. gotoana influenced by seed harvest dates (maturity) and with CS.

\section{Materials and Methods}

Plant materials. Seeds were harvested from Corylopsis coreana Uyeki from a population of stock plants grown from seeds initially collected from Namhae, Gyongsangnamdo, Korea, and from C. gotoana Makino collected from Kyushu, Japan. Seeds of both species were packed in a moist Pro-Mix BX medium (50\% moisture) and received $5{ }^{\circ} \mathrm{C}$ treatment (CS) and germinated as described by Kim et al., (2016). Seeds were sown in a $15-\mathrm{cm}$ pot filled with a Pro-Mix BX (Premier Horticulture Inc., Quakertown, PA) growing medium and received temperature treatments as specified in each experiment. When hypocotyls emerged from the sowing medium, seeds were recorded as germinated. Each treatment was replicated two or three times, with the number of seeds per replication specified in each experiment.

Germination of C. gotoana seeds influenced by seed harvest dates and X-ray images (Expt. 1). Corylopsis gotoana fruits harvested on 12 July, 2 and 22 Aug., 6 and 20 Sept., and 1 and 10 Oct. 2011 were kept at $20^{\circ} \mathrm{C}$ for 3 to $4 \mathrm{~d}$ and seeds were separated from the fruits. Weights of 10 individual seeds that either sank or floated after immersing in water for $20 \mathrm{~min}$, except for seeds harvested on 12 July, were recorded. Seeds that were harvested from 20 Sept. onward were easily separated from the fruits; the fruits turned brown and started to split open showing seeds inside.

Seeds that sank or floated were air-dried at $20{ }^{\circ} \mathrm{C}$, stored dry at $5{ }^{\circ} \mathrm{C}$, and sown on 17 Nov. and germinated in a growth chamber as described by Kim et al. (2017). The number of seeds per replication harvested on 12 July and 2 Aug. was 15 and 39 seeds, respectively, while seeds harvested on 22 Aug. or later contained 100 seeds per replication; there were three replications per treatment (Table 1). Germination of X-ray imaged seeds following exposure to $20 \mathrm{kV}$ for $15 \mathrm{~s}$ was as described previously (Kim et al., 2017). After 30 consecutive days without additional germination, pots were moved on
29 Jan. 2012 for CS for 3 months, and returned to the growth chamber, where germination was recorded daily.

Only the data for seeds germinated by the first week after planting and the final germination percentages are presented. Regression analyses were performed following arcsine transformation (Statistical Analysis System, 2002). The means were transformed to the original data and presented. The number of days to the final germination and the germination percentages were presented.

Germination of $C$. coreana seeds influenced by seed harvest dates and duration of cold treatment (Expt. 2). Corylopsis coreana seeds harvested on 5 and 15 Sept. and 5 and 18 Oct. 2011 were stored dry at $20{ }^{\circ} \mathrm{C}$ until $27 \mathrm{Dec}$. 2011. Only seeds that sank after immersing in water for $15 \mathrm{~min}$ were packed in moist Pro-Mix BX and treated for $0,3,6,9$, and 12 weeks of CS. Another group of $C$. coreana seeds harvested on 18 Oct. was treated for $0,3,6,9$, and 12 weeks of CS. The number of days to final germination and germination percentage were presented. Another group of $C$. coreana seeds harvested on 18 Oct. was treated for 0 , $3,6,9$, and 12 weeks of CS and the germination percentage and number of seeds that germinated was recorded.

After CS, pots were placed in the growth chamber maintained at $21 / 18{ }^{\circ} \mathrm{C}$ and the number of seeds germinated was recorded at 1 to 3 day intervals until no additional seeds germinated consecutively for $14 \mathrm{~d}$. Treatment was replicated twice with 100 seeds per replication. Data were subjected to ANOVA with harvest dates and the duration of CS as variables, and the means were compared by Tukey's honestly significant difference test at $1 \%$ significance level.

\section{Results and Discussion}

Germination of C. gotoana seeds influenced by seed harvest dates (maturity) and X-ray images (Expt. 1). Fruits of C. gotoana harvested on 12 July were green and very tight and seedcoats in most of the seeds were milky yellow. Only one seed weighing $14.3 \mathrm{mg}$ sank. The weight of seeds harvested on or after 6 Sept. that sank was greater than $18.9 \mathrm{mg}$ per seed, heavier than those that floated, which ranged between 14.3 and $16.3 \mathrm{mg}$ (Table 1).The seed weight increased with delay in harvest dates. The percentage of seeds that sank increased significantly when seeds were harvested on 6 Sept. (59\%) or 10 Oct. (73\%).

Corylopsis gotoana seeds that were harvested on 1 Oct. and did not receive any CS germinated up to $25 \%$ for those that sank and $20 \%$ for those that floated (Table 1). The difference in the germination of seeds that sank and floated in the first week did not differ significantly, especially when seeds were harvested between 6 Sept. and 1 Oct. The final germination percentages following 3 months of CS were unaffected by whether seeds sank and floated, perhaps due to a low percentage of seeds that sank when seeds were harvested on 12 July. Late harvested seeds that floated germinated at $41 \%$ (10 Oct. harvest) to $54 \%$ (20 Sept. harvest); however, percentages were significantly lower than the percentages of seeds that sank.

Morphological differences related to the development of fruits were not recorded. However, based on the seed weight, the number of seeds that sank, and germination percentages, the 3 month harvest period clearly covered development stages ranging from immature seeds before 22 Aug. to mature seeds with fully developed internal structures (Kim et al., 2017) harvested on or after 6 Sept. If seeds are harvested and germinated as early as possible and grown under favorable environmental conditions, larger seedlings could be forced to flower in the next season one year after transplanting seedlings.

Immersing $C$. gotoana seeds for $20 \mathrm{~min}$ may not effectively separate fully developed seeds that sink from empty seeds nor accurately estimate the germination percentages. Increasing the immersion time up to $16 \mathrm{~h}$ increased the percentage of seeds that sank and improved the seed germination in both $C$. coreana and $C$. sinensis var. calvescens (Kim et al., 2017). Corylopsis seeds are very small and using the floating technique for $16 \mathrm{~h}$ or longer facilitates separation of full and

Table 1. Percentage of seeds that sank when immersed in water, weight of each seed, and germination percentages according to different harvest dates in Corylopsis gotoana

\begin{tabular}{|c|c|c|c|c|c|c|c|}
\hline \multirow{2}{*}{ Harvest date } & \multirow{2}{*}{ Seeds that sank (\%) } & \multirow{2}{*}{\multicolumn{2}{|c|}{ Wt of seed (mg) }} & \multicolumn{4}{|c|}{ Germination $(\%)^{\mathrm{z}}$} \\
\hline & & & & \multicolumn{2}{|c|}{ Week 1} & \multicolumn{2}{|c|}{ Final } \\
\hline 12 July & $0 \mathrm{~d}^{\mathrm{x}}$ & $14.3 \mathrm{~d}$ & $13.2 \mathrm{c}$ & $0 \mathrm{~d}$ & $3 \mathrm{~d}$ & $0 \mathrm{c}$ & $50 \mathrm{a}$ \\
\hline 22 Aug. & $46 \mathrm{c}$ & $17.0 \mathrm{~b}$ & $13.6 \mathrm{c}$ & $12 \mathrm{~b}$ & $6 \mathrm{c}$ & $73 \mathrm{a}$ & $52 \mathrm{a}$ \\
\hline 6 Sept. & $59 \mathrm{~b}$ & $18.9 \mathrm{a}$ & $14.3 \mathrm{~b}$ & $7 \mathrm{c}$ & $7 \mathrm{c}$ & $82 \mathrm{a}$ & $41 \mathrm{~b}$ \\
\hline 20 Sept. & $61 \mathrm{~b}$ & $19.0 \mathrm{a}$ & $14.7 \mathrm{~b}$ & $14 \mathrm{~b}$ & $14 \mathrm{ab}$ & $68 \mathrm{a}$ & $54 \mathrm{a}$ \\
\hline 1 Oct. & $69 \mathrm{ab}$ & $19.2 \mathrm{a}$ & $15.3 \mathrm{a}$ & $25 \mathrm{a}$ & $20 \mathrm{a}$ & $69 \mathrm{a}$ & $50 \mathrm{a}$ \\
\hline Harvest time - quadratic effect & $* * *$ & $* * *$ & & $* * *$ & & $* * *$ & \\
\hline Sank vs. Floated seeds & - & $* * *$ & & NS & & NS & \\
\hline
\end{tabular}

${ }^{\mathrm{z}}$ Germination data were collected 1 week after sowing (week 1) without CS and following 3 months of CS (final on 19 June).

${ }^{\mathrm{y}}$ Seeds were immersed in water for $20 \mathrm{~min}$ and those that sank and floated were collected separately.

${ }^{\mathrm{x}}$ Mean separation within columns by Duncan's multiple test. Means with different letters in a column are not significantly different from each other

ss, ***Nonsignificant or significant at $P \leq 0.001, \mathrm{~F}$ test. 
mature seeds from immature and empty seeds on a large scale, especially when X-ray scanning is not available. Immersing Casuarina equisetifolia seeds in petroleum (Sivakumar et al., 2007) or Crimean pine [Pinus nigra Arn. ssp. pallasiana (Lamb.)] Holmboe (Avsar, 2010) in ethanol suggest that separation of Corylopsis seeds that can germinate should further be evaluated by testing various organic solvents.

The weight of seeds that sank cannot be used to determine when to harvest mature seeds, perhaps due to great variability in weight among individual seeds. A few seeds appeared to be semifull as revealed by X-ray images (Kim et al., 2017). X-ray images of seeds harvested on 6 Sept. (Fig. 1) are not very clear compared with images of castor bean (Ricinus communis L.) seeds (Carvalho et al., 2010). The possible reasons include enlargement of small Corylopsis seeds or resolution of the device compared with the castor bean study. Differences in the imaging conditions may also play a role following exposure to $20 \mathrm{kV}$ for $15 \mathrm{~s}$ in this study compared with $20-50 \mathrm{kV}$ for $15-75 \mathrm{~s}$ for castor bean. Seeds that were categorized as semifull may either sink or float depending on the degree of development of internal structure. Seeds that were harvested early on 12 July (Fig. 2, Frame A) showed as emptier than full or semifull seeds which can be used to determine the seed quality as reported for castor beans (Carvalho et al., 2010). Delay in harvest date to 10 Oct. (Frame $\mathrm{G}$ ) resulted in only four empty seeds and one semifull seed while the remaining $69 \%$ of the seeds were full seeds. The relationship between the weights of seeds,
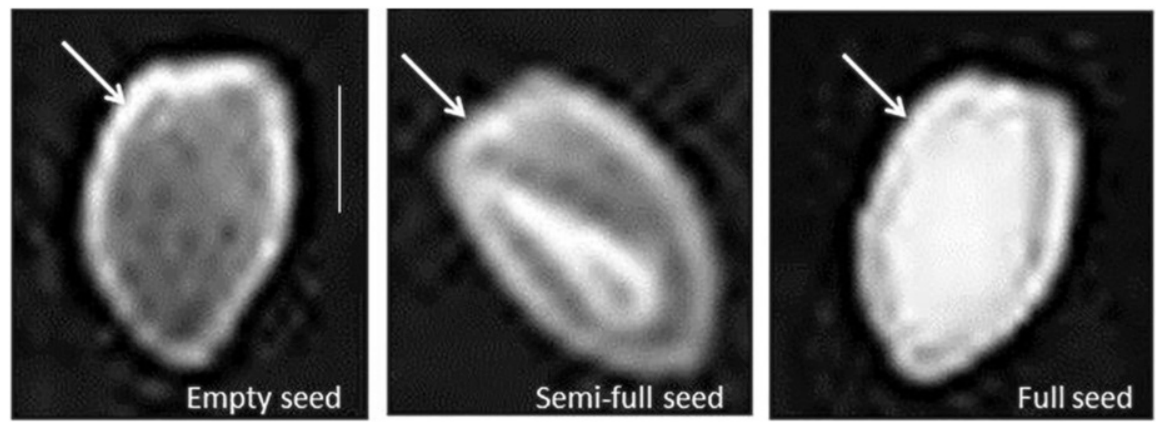

Fig. 1. X-ray images of C. gotoana seeds harvested on 6 Sept.; empty seed showing only seedcoat (arrow), semifull seeds with deformed or partially full and blemished internal structure, and full and opaque seed with developed internal structure. Approximate size of seeds: Bar $=1 \mathrm{~mm}$.

the percentage of germinating seeds, and seeds showing fully developed internal structures warrants careful scrutiny, since a few floated seeds germinated, and also due to difficulties in classifying empty, semifull and full seeds based on X-ray images of seeds harvested in July and August.

Germination of $C$. coreana seeds influenced by seed harvest dates (maturity) and duration of cold treatment (Expt. 2). Corylopsis coreana seeds that sank following immersion into water were used for germination tests to evaluate the effect of seed harvest date (maturity) and CS for up to 12 weeks at 3-week intervals. Regardless of seed harvest date, seeds failed to germinate without CS and less than $15 \%$ of seeds germinated when given 3 weeks of CS (Fig. 3). When seeds were harvested on or after 15 Sept., germination was promoted by 9 weeks of CS to higher than $55 \%$. Regardless of seed harvest dates, more than $60 \%$ of the seeds germinated when given 12 weeks of CS.

Increasing the duration of $\mathrm{CS}$ also accelerated the germination (Fig. 4) from 25 and $26 \mathrm{~d}$ following 3 to 6 weeks of CS, to less than $19 \mathrm{~d}$ when given CS for 9 or 12 weeks. Without CS, seeds achieved only $8 \%$ germination in $44 \mathrm{~d}$, and germination started from 26 to $27 \mathrm{~d}$ after sowing (Roh et al., 2008). Upon 12 weeks of CS, the germination plateau of $69 \%$ was reached within $\sim 29 \mathrm{~d}$.

\section{Conclusions}

Based on the percentage of seeds that sink and germinate, $C$. gotoana seeds can be
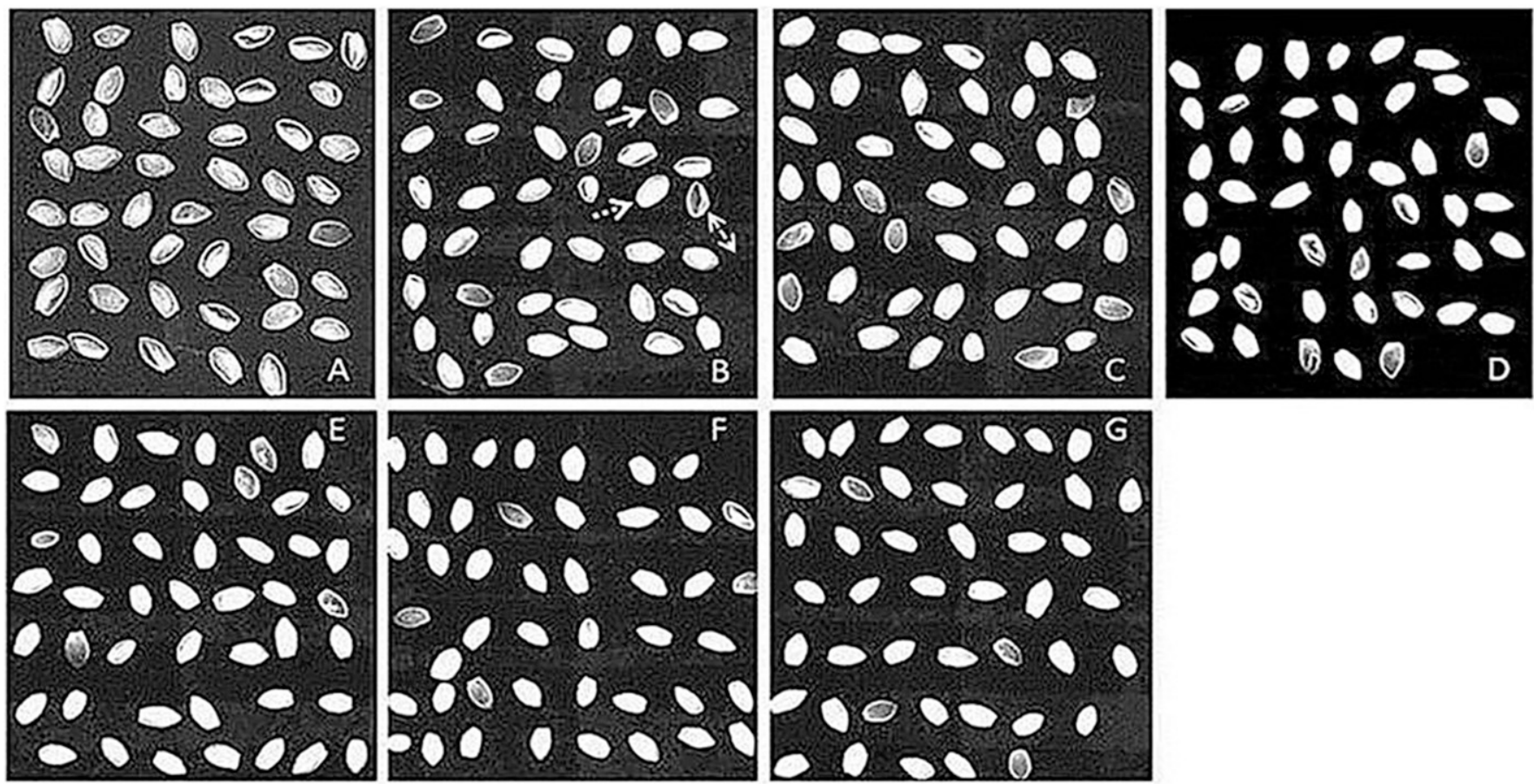

Fig. 2. X-ray images of C. gotoana seeds harvested on 12 July (frame A), 2 Aug. (frame B), 22 Aug. (frame C), 6 Sept. (frame D), 20 Sept. (frame E), 1 Oct. (frame F), and 10 Oct. (frame G). In Frame B, empty seeds (solid arrow) that floated when harvested early rather than late with more full seeds that sank (dotted arrow). Semifull seeds are indicated by double-headed dotted arrow. More empty and semifull seeds were observed when seeds were harvested early (Frames A $>B>C$ ) and full seeds when harvested late (Frames $\mathrm{D}<\mathrm{E}<\mathrm{F}<\mathrm{G}$ ). 
$\square$ Sept. $5 \square$ Sept. $15 \mathbb{Q}$ Oct. $5 \quad \square$ Oct. 18
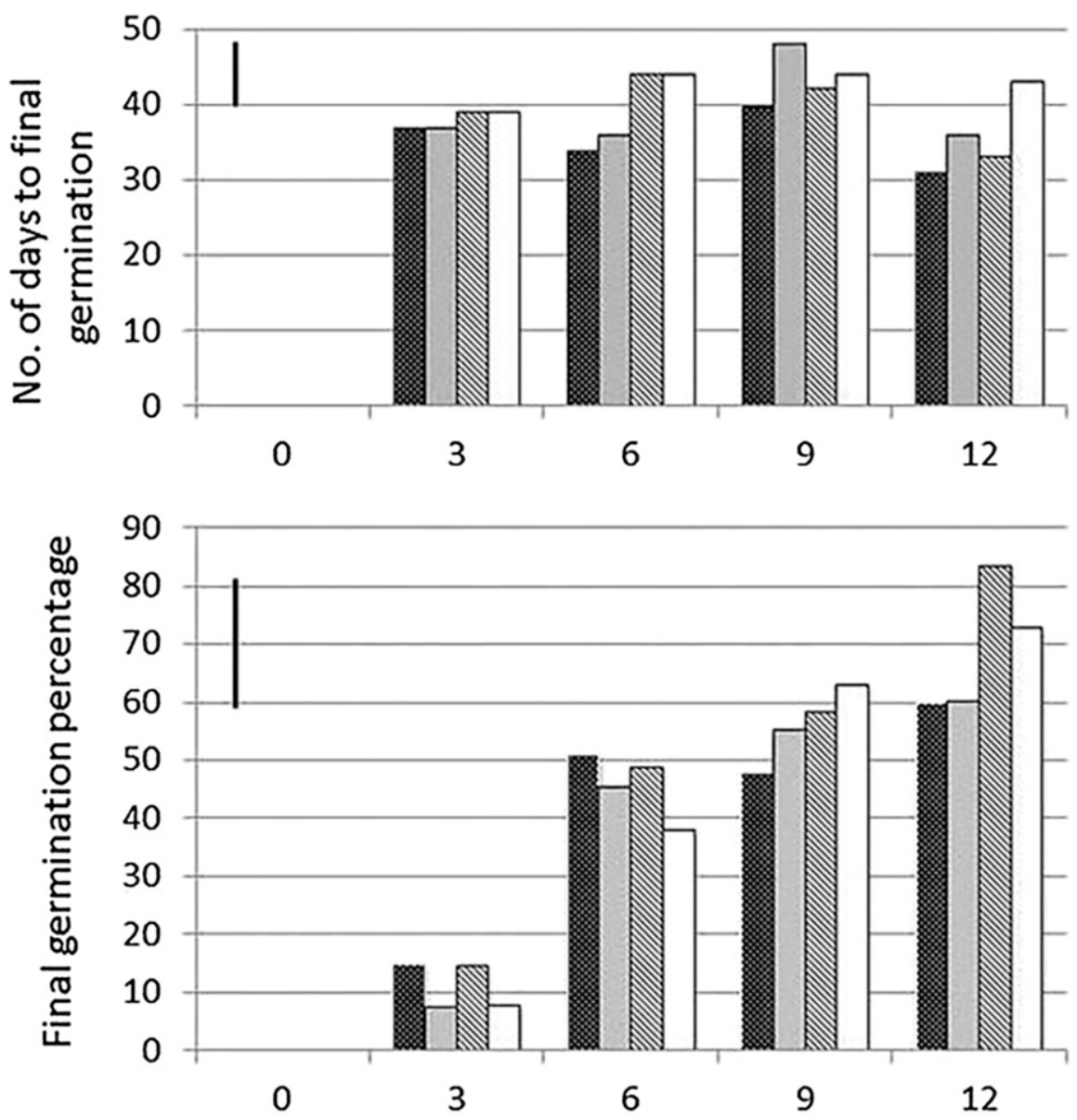

No. of weeks at $5^{\circ} \mathrm{C}$

Fig. 3. Number of days to final germination and final germination percentage of $C$. coreana seeds harvested at different dates as influenced by the number of weeks at $5{ }^{\circ} \mathrm{C}$. Bar indicates significant different level by honestly significant difference at $5 \%$ level, $\mathrm{F}$ test.

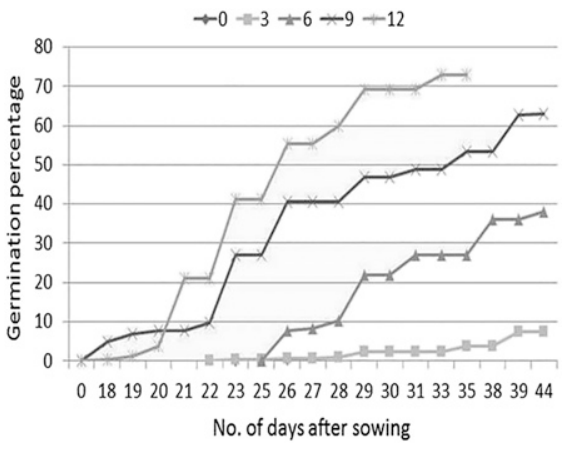

Fig. 4. Germination of C. coreana seeds harvested on 18 Oct. as influenced by the number of weeks at $5{ }^{\circ} \mathrm{C}$.

harvested as early as $22 \mathrm{Aug}$. and C. coreana around 15 Sept. to obtain nearly $70 \%$ germination. Therefore, it is concluded that mature seeds of $C$. coreana and $C$. gotoana can be harvested on or around 6-20 Sept., about 20-22 weeks after anthesis in mid-March. In Styrax japonicus, mature seeds that subsequently germinated were harvested 12 to 16 weeks harvested on or after 5 Sept. Six weeks of CS accelerates the germination and increases the germination percentage. Most interestingly, partial germination of seeds that were not treated with CS suggests that Corylopsis seed dormancy is not deep. Further investigations are needed to develop efficient methods to separate fully developed and mature seeds from partially developed or empty immature seeds.

\section{Literature Cited}

Avsar, M.D. 2010. Using flotation in ethanol to separate filled and empty seeds of Pinus nigra ssp. pallasiana. Afr. J. Biotechnol. 9:3822-3827.

Baskin, C.C., O. Zackrisson, and J.M. Baskin. 2002. Role of warm stratification in promoting germination of Empetrum hermaphroditum (Enoetraceae), a critical species with a stony endocarp. Amer. J. Bot. 89:486-493.

Baskin, J.M. and C.C. Baskin. 2004. A classification system for seed dormancy. Seed Sci. Res. 14:1-16.

Batlla, D. and R.I. Benech-Arnold. 2003. A quantitative analysis of dormancy loss dynamics in Polygonum aviculare L. seeds: Development of a thermal time model based on changes in seed population thermal parameters. Seed Sci. Res. 13:55-68.

Bewley, J.D. 1997. Seed germination and dormancy. Plant Cell 9:1055-1066.

Carvalho, M.L.M., R.A. Alves, and L. Magda de Oliveira. 2010. Radiographic analysis in castor bean seeds (Ricinus communis L.). Rev. Bras. Sementes 32:170-175.

Dirr, M. 1990. Manual of woody landscape plants: Their identification, ornamental characteristics, culture, propagation and uses. Stipes Publishing Co., Champaign, IL.

Finch-Savage, W.E. and G. Leubner-Metzger. 2006. Seed dormancy and the control of germination. New Phytol. 171:501-523.

Hilhorst, H.W.M. 2007. Definition and hypothesis of seed dormancy, p. 50-71 In: K. Bradford and H. Nonogaki (eds.). Annual Plant Reviews Vol. 27. Seed development, dormancy and germination. Wiley-Blackwell Publishing, Oxford, UK.

after anthesis (Roh et al., 2004). To maximize germination, longer than 6 weeks of CS is desirable, although a few C. coreana and $C$. gotoana seeds germinate without CS treatments.

Immersing $C$. gotoana seeds in water for $20 \mathrm{~min}$ did not effectively separate fully developed seeds from empty seeds, since more than $20 \%$ of seeds harvested on 1 Oct. that floated had germinated. Seed weight cannot be used to determine maturity. Mature C. gotoana seeds that sank upon immersing in water showed translucent X-ray images, representing well-developed internal structure when seeds were harvested on or around 6 Sept. Without any cold treatment, seeds germinated regardless of seed maturity showing $>14 \%$ or $>23 \%$ when seeds were harvested on or after 20 Sept. Longer than 6 weeks of CS was required to accelerate the germination and germination percentages of C. coreana seeds harvested on or after 5 Sept. Germination percentage of mature seeds harvested on 18 Oct. was increased to $>72 \%$ as the duration of CS was increased to 12 weeks. Mature C. coreana seeds can be
Kim, J.H., K.O. Kim, A.K. Lee, M.S. Roh, and J.K Suh. 2017. Germination of Corylopsis seeds evaluated by X-ray imaging and cold stratification. Hortic. Sci. (Prague) 44:105-111.

Kim, J.H., A.K. Lee, and J.K. Suh. 2016. Effect of warm and cold stratification and ethanol treatment on germination of Corylopsis seeds. Hort. Sci. (Prague) 43:84-91.

Roh, M.S., J.A. Bentz, P. Wang, E. Li, and M. Koshioka. 2004. Maturity and temperature stratification affect the germination of Styrax japonicus seeds. J. Hort. Sci. Biotechnol. 79:645-651.

Roh, M.S., A.K. Lee, J.K. Suh, and C.M. Bordelon. 2008. Interspecific variations in seed germination of Corylopsis. Scientia Hort. 118:347-350.

Roh, M.S., A.K. Lee, I.Y. Choi, J.Y. Kim, Y.H. Joung, S.H. Lee, and J.K. Suh. 2007. Characterization of the Corylopsis coreana using molecular markers. Hort. Environ. Biotechnol. 48:176-187.

Sivakumar, V., R. Anandalakshmi, R.R. Warrier, B.G. Singh, M. Taigabu, and P.C. Odén. 2007. Petroleum flotation technique upgrades the germinability of Casuarina equisetifolia seed lots. New For. 34:281-291.

Statistical Analysis System (SAS). 2002. SAS proprietary software version 9.00. SAS Institute, Inc., Cary, NC. 